\section{Por que os homens buscam menos os serviços de saúde do que as mulheres? As explicações de homens com baixa escolaridade e homens com ensino superior}

\author{
Why do men use health services less than women? \\ Explanations by men with low versus higher \\ education
}

\section{Instituto Fernandes Figueira, Fundação Oswaldo Cruz, Rio de Janeiro, Brasil. \\ Correspondência \\ R. Gomes \\ Departamento de Ensino, Instituto Fernandes Figueira Fundação Oswaldo Cruz. Av. Rui Barbosa 716, Rio de Janeiro, RJ 22250-020, Brasil. romeu@iff.fiocruz.br}

\begin{abstract}
The objective of this study was to analyze explanations in male discourse for men's relatively limited use of health services, using a qualitative methodology. Representation of caring as a female task, work-related issues, difficult access to services, and lack of services specifically targeting men's health were the main reasons for their limited use of health services. By way of conclusion, the social imaginary by which men are viewed as invulnerable leads them to take less care of their own health and expose themselves to greater risk.
\end{abstract}

Men's Health; Health Services; Gender Identity
Romeu Gomes 1

Elaine Ferreira do Nascimento ${ }^{1}$

Fábio Carvalho de Araújo 1

\section{Introdução}

Vários estudos constatam que os homens, em geral, padecem mais de condições severas e crônicas de saúde do que as mulheres e também morrem mais do que elas pelas principais causas de morte 1,2,3. Entretanto, apesar de as taxas masculinas assumirem um peso significativo nos perfis de morbimortalidade, observa-se que a presença de homens nos serviços de atenção primária à saúde é menor do que a das mulheres 4,5 .

Há autores que associam esse fato à própria socialização dos homens, em que o cuidado não é visto como uma prática masculina $1,6,7$. Na literatura específica sobre o assunto, também há vários estudos que apontam a necessidade de se refletir sobre a masculinidade para uma compreensão dos comprometimentos da saúde do homem 1,8,9,10,11.

Nesse sentido, devem ser realizados estudos que contemplem a historicidade da masculinidade, caminhando desde o surgimento dessa expressão como diferenciação dos sexos até a sua incorporação nos estudos de gênero 12,13. A categoria gênero, neste estudo, está sendo entendida como atributos e funções - socialmente construídos - que configuram diferenças e inter-relações entre os sexos, que vão para além do biológico 9 . Assim, ser homem ou ser mulher implica a incorporação desses atributos e funções, como forma de representar-se, valorizar-se e atuar numa determinada cultura ${ }^{9}$. 
Ampliando a discussão, verifica-se que as relações homens/mulheres e homens/homens costumam ser vistas a partir do produto de dois modelos naturalistas: a dominação dos homens e a perspectiva heterossexuada do mundo 14 . Nesse cenário, os homens também se tornam prisioneiros, uma vez que o privilégio masculino pode ser uma cilada, fazendo com que a todo custo o homem tenha de provar a sua virilidade, deixando de fora enternecimentos desvirilizantes do amor 15.

O ideal de homem (viril, forte, invulnerável e provedor), entretanto, vem sendo abalado a partir dos questionamentos dos movimentos feministas (anos 70) e de gays (anos 80). Tais questionamentos, que rechaçam as bases naturalistas da dominação masculina, possibilitaram abrir um imenso campo de pesquisas que abarcassem a discussão da masculinidade a partir de outro enfoque 16 .

Embora haja uma ampla discussão sobre masculinidade na área da saúde em geral, ainda há uma insuficiência de estudos sobre o empenho masculino voltado para o estilo de vida saudável e a promoção da saúde 1 . Para se avançar nessa discussão, dentre outros aspectos, é importante dar voz aos próprios homens para melhor compreender as questões envolvidas no seu acesso aos serviços de saúde.

A partir dessa perspectiva, objetiva-se analisar as explicações presentes em discursos masculinos sobre a pouca procura dos homens por serviços de saúde. Essa análise pode ser importante para se refletir sobre as dificuldades, os obstáculos e as resistências associadas à saúde do homem numa dimensão relacional de gênero.

\section{Material e método}

O presente estudo é parte de uma investigação que se volta para A Construção da Masculinidade como um Fator Impeditivo do Cuidar de Si, que teve como eixo central a discussão sobre prevenção do câncer prostático, a partir de uma revisão da literatura e de entrevistas com 28 homens, sendo dez com baixa escolaridade, oito com ensino superior e dez médicos. Nessa investigação, procurou-se problematizar os discursos acerca desse tipo de prevenção. A procura de serviços de saúde por parte de homens - foco deste estudo - é parte dessa pesquisa.

Na pesquisa original, o "cuidar de si" baseouse na contribuição Foucaultiana que discute a "intensificação da relação consigo pela qual o sujeito se constitui enquanto sujeito de seus atos" 17 (p. 47). Nessa discussão, se destaca que, desde a tradição grega, o cuidar de si se relaciona com o pensamento e a prática médica, traduzindo-se na atenção com o corpo. Tal idéia serviu como mote para a discussão da procura masculina por serviços de saúde. Embora tal procura não traduza necessariamente uma preocupação com o “cuidar de si”, nem tão pouco a reduza, não se pode desconsiderar que, numa sociedade em que não é usual o homem se ocupar de si, a busca por serviços de saúde pode ser associada a essa preocupação.

Neste estudo, foram seguidos princípios da pesquisa qualitativa, aqui entendida como práticas interpretativas que contemplam os sentidos que os sujeitos atribuem aos fenômenos e ao conjunto de relações em que eles se inserem 18,19. Tal abordagem se ancora na hermenêutica-dialética, que articula uma atitude hermenêutica (voltada para o sentido do que é consensual da mediação e do acordo) e um posicionamento dialético (orientado para a diferença, o contraste, o dissenso, a ruptura de sentido) 20 . A partir desses princípios, caminhou-se na compreensão e na contextualização dos sentidos atribuídos ao ser homem e da pouca procura masculina por serviços de saúde.

Os sujeitos deste estudo foram selecionados com base em uma prática bastante usual em pesquisa social sobre os universos familiares 21,22, em que pessoas conhecidas do pesquisador indicam outras a serem entrevistadas, que, por sua vez, indicam outras conhecidas. Ao longo da pesquisa, nem sempre foi possível contar com a indicação de uma pessoa conhecida dos entrevistados, fazendo com que novas cadeias de informantes fossem iniciadas.

A amostra de conveniência foi composta a partir dos seguintes princípios: (i) escolher os sujeitos que detêm os atributos relacionados ao que se pretende estudar (no caso deste trabalho se trata de homens a partir de quarenta anos, residentes ou que trabalhem na cidade do Rio de Janeiro, Brasil); (ii) considerar tais sujeitos em número suficiente para que possa ter reincidência das informações; (iii) considerar a possibilidade de inclusões sucessivas de sujeitos até que seja possível uma discussão densa das questões da pesquisa. Assim, a amostra não buscou uma representatividade numérica e sim um aprofundamento da temática 23

Neste estudo, estão sendo focalizados 18 homens, divididos em dois grupos: homens com baixa ou nenhuma escolaridade (aqui denominados de Grupo I) e homens com o Ensino Superior (denominados de Grupo II). Essa composição foi pensada para problematizar as possíveis influências do grau de instrução na pouca procura de serviços de saúde por parte de homens. 
Os entrevistados tinham quarenta anos ou mais dado que, na pesquisa original do estudo, o foco era prevenção de câncer de próstata, que costuma focalizar esta faixa etária.

O Grupo I foi composto por dez homens com idades entre 45 e 57 anos. Seus integrantes se autodeclararam, em sua maioria, pardos. Nove deles cursaram até a quarta série do Ensino Fundamental e um respondeu não ter nenhuma instrução. Entre eles, nove eram casados e um afirmou ser solteiro. A renda mensal dos entrevistados apresentou uma média de 3,3 salários mínimos, sendo que o menor rendimento foi de um salário mínimo e o maior foi de oito salários mínimos. Na época da coleta das informações, em 2004, o salário mínimo do Estado do Rio de Janeiro era de $\mathrm{R} \$ 305,00$. Entre as atividades exercidas, destacaram-se as de carpinteiro, pintor e armador, além de ascensorista, mestre de serviços operacionais, pedreiro e servente. A maioria deles residia em municípios vizinhos à cidade do Rio de Janeiro.

No Grupo II, os entrevistados tinham entre 40 e 64 anos e se autodeclararam brancos (num total de quatro) e pretos ou pardos (num total de dois cada). Em relação ao estado civil, quatro eram casados e quatro solteiros. A renda mensal dos entrevistados apresentou uma média aproximada de 15 salários mínimos, sendo que o menor rendimento foi de oito salários mínimos e o maior foi de 20 salários mínimos. Entre as atividades exercidas, foram verificadas as profissões de professor, psicólogo, engenheiro, advogado e economista. Todos residiam na cidade do Rio de Janeiro.

A coleta dos dados se apoiou em entrevistas semi-estruturadas, realizadas em horários e locais escolhidos pelos entrevistados. Nesse tipo de coleta, procurou-se estabelecer uma conversa dirigida com os pesquisados em torno de temas que integravam o objeto da pesquisa. Neste trabalho serão abordados os temas ser homem e procura de serviços de saúde.

Em termos de tratamento dos depoimentos, utilizou-se o método de interpretação de senti$d o s$, baseando-se em princípios hermenêuticosdialéticos que buscam interpretar o contexto, as razões e as lógicas de falas, ações e inter-relações entre grupos e instituições 24 .

A trajetória analítico-interpretativa percorreu os seguintes passos: (i) leitura compreensiva, visando à impregnação, visão de conjunto e apreensão das particularidades do material gerado pela pesquisa original; (ii) identificação e recorte temático dos depoimentos acerca das seguintes questões: ser homem e menor procura pelos serviços de saúde por parte do homem em comparação à mulher; (iii) identificação e problemati- zação das idéias explícitas e implícitas no texto; (iv) busca de sentidos mais amplos (sócio-culturais) que articulam as explicações dos sujeitos da pesquisa; (v) diálogo entre as idéias problematizadas, informações provenientes de outros estudos acerca do assunto e o referencial teórico do estudo; e (vi) elaboração de síntese interpretativa, procurando articular o objetivo do estudo, base teórica adotada e dados empíricos.

$\mathrm{O}$ projeto de pesquisa do qual se insere este trabalho foi avaliado pelo Comitê de Ética em Pesquisa com Seres Humanos do Instituto Fernandes Figueira, Fundação Oswaldo Cruz, em cumprimento da Resolução no. 196/96 do Conselho Nacional de Saúde. Para garantir o caráter sigiloso das informações, os depoimentos dos entrevistados serão codificados com nomes fictícios iniciados pela letra "A" para os homens do Grupo I e com a letra “M” para os do Grupo II.

\section{O imaginário de ser homem}

Antes de os entrevistados opinarem acerca da idéia de homens procurarem menos os serviços de saúde do que as mulheres, eles foram convidados a refletir sobre o que é ser homem. Responder a essa pergunta foi difícil para a maioria deles, principalmente para os que possuíam baixa ou nenhuma escolaridade (Grupo I).

Observou-se que, independentemente do nível de escolaridade, os entrevistados lançavam mão de idéias contrárias para definir ser homem em oposição ao ser mulher. Essa lógica reflete a diferença atribuída entre os gêneros para se demarcar a especificidade de cada um deles. Assim, enquanto o homem é "bruto", "forte", "agressivo", "tem iniciativa sexual (ativo)", "vive mais na rua" e "gosta de pular a cerca (é sexualmente infiel)"; a mulher é "suave", "sensível”, "doce”, sexualmente mais "passiva", "fica mais em casa" e sexualmente "se segura mais".

No Grupo II, os entrevistados ensaiaram explicações para as diferenças entre os gêneros. Nas suas explicações, utilizaram conteúdos relacionados tanto a aspectos biológicos quanto a culturais:

“A constituição física é diferente (...) os hormônios que correm são diferentes (...) por isso (...) algumas sensações também são diferente" (Marcos).

“Em função de ser uma sociedade machista (...) a reação masculina (...) é muito mais física em situações de limite do que a feminina" (Mário).

A defesa da influência dos aspectos culturais na masculinidade, por parte de alguns entrevistados, reforça a idéia de que, em geral, nas diversas culturas, a educação dos meninos se- 
gue padrões de oposição entre os gêneros. Nesse sentido, os homens são estimulados a manifestar a sua virilidade por meio da rejeição de comportamentos tidos como femininos 25 para se constituírem como homens 14. Assim, o padrão de masculinidade é idealizado por meninos e homens não pelo desejo de serem viris, mas pelo medo de serem vistos como pouco viris ou afeminados 26 .

Junto às idéias hegemônicas sobre o que é ser homem, também estava presente a opinião de que há diferentes estilos de masculinidade: “Tem homens (...) delicados e outros não. (...) Tem homem amoroso [e] tem um que não é. (...) Tem homem que é agressivo (...) outro já é mais calmo" (Almir).

Outro posicionamento se referiu à idéia de que, no ser homem, há uma parte do feminino: "Eu não descarto até que eu tenha essa parte feminina (...) eu acho que todo homem tem e tem que (...) deixar aflorar isso para (...) entender o outro lado [o ser mulher]" (Marcelo).

No entanto, a demonstração desses sentimentos tidos como femininos ainda pode sofrer interdições. Como disse um entrevistado: "Eu descobri que o homem podia chorar (...) podia ter sentimentos (...) mas dentro de uma ação (...) de natureza sigilosa" (Miguel).

Essas opiniões, mesmo com certas restrições, apontam para uma mudança, a ponto de o homem poder assumir algumas atitudes "que antes eram de exclusividade da mulher (...) sem se confundir com a mulher" (Marcos).

$\mathrm{Na}$ construção das respostas dos entrevistados à questão do que é ser homem, principalmente entre os do Grupo I, a idéia da heterossexualidade é um eixo estruturante da masculinidade, uma vez que "O homem não deve ser gay. $O$ homem não deve ser bicha (...)” (Almir) e "Ele tem que procurar mulher" (Alberto).

Entre os entrevistados do Grupo II, a homossexualidade é mais tolerada, embora nem sempre se consiga vivê-la socialmente. Assim, "[Homens que] têm um companheiro igual a ele mesmo (...) não deixam de ser homem também. (...) Mas tem a vida deles (...) meio isolada" (Maurício).

A homossexualidade também se apresenta como um conteúdo até certo ponto problemático em outros estudos. Dados de uma pesquisa nacional - realizada em 2002 com uma amostra probabilística de 2.364 informantes - são ilustrativos ao verificar que houve "unânime rejeição ao homossexualismo masculino e feminino: $89 \%$ são contra o primeiro e $88 \%$ contra o segundo" 27 (p. 66).

Os entrevistados, independente do grau de escolaridade, também associaram ao ser homem valores morais e éticos.
"[O homem tem que ter] responsabilidade (...) nas suas tarefas, suas atitudes (...) ter palavra, ter moral" (Almiro).

"[Tem que] ter um comportamento ético" (Mário).

Esses valores podem ter como reflexo um discurso sobre o controle da sexualidade masculina, que aparece de uma forma contraditória: “[O homem] não tem um controle (...) quer saciar o desejo dele a todo o momento. (...) Bom, a vida sexual (...) eu não exagerava. Eu controlava. (...) Tem que se controlar, não é?" (Almiro).

Esse depoimento pode sugerir que, ao mesmo tempo, que se propala uma sexualidade masculina desenfreada, se depara com limites impostos por regras sociais que devem ser obedecidas.

Em síntese, os homens dos dois grupos trouxeram idéias alternativas àquelas predominantes no senso comum sobre o ser homem. Eles reforçaram a existência das masculinidades, no plural 26. A idéia sobre a co-existência de modelos de masculinidade é discutida por Cecchetto 28, que se baseia na concepção de Kimmel acerca das relações entre masculinidades hegemônicas e subordinadas: "Na tentativa de se conferirem uma masculinidade socialmente valorizada, certos grupos masculinos negam outras versões de homem, transformando-as em duvidosas e despreziveis" 28 (p. 66). Por ter ascendência sobre os outros modelos, a masculinidade hegemônica é tida como ideal, mas nem sempre é seguida por todos os homens 28 .

\section{Explicações para a pouca procura dos serviços de saúde por parte dos homens}

Inicialmente faz-se necessário observar que "pouca procura" neste estudo não está relacionada com o consumo de serviços de saúde, não cabendo aqui uma mensuração entre oferta e demanda. Tal expressão se remete a hábitos de prevenção que usualmente são mais associados às mulheres do que aos homens.

Todos os entrevistados concordaram com a afirmação de que os homens procuram menos os serviços de saúde do que as mulheres, embora alguns deles tenham feito críticas no sentido de que esses serviços deveriam ser procurados pelas pessoas, independentemente do gênero.

As explicações elaboradas pelos entrevistados giram em torno de um único eixo estruturante: papéis a serem desempenhados para que se ateste a identidade de ser masculino. Nesse sentido, a procura por serviços de saúde se encontra intimamente relacionada ao que se entende por ser homem. 
A primeira explicação latente nas respostas dos entrevistados se refere à associação do cuidar ao âmbito feminino. Essa explicação estrutura as opiniões de que "a mulher se cuida mais do que o homem" (Almir) e o homem "não foi muito criado para se cuidar" (Marcos).

Essa opinião reforça estudos que apontam as diferenças de papéis por gênero presentes no imaginário social, entendendo os cuidados como próprios do âmbito feminino 7,29,30. Isso se justificaria pela socialização que as mulheres recebem, desde cedo, para reproduzirem e consolidarem os papéis que as tornam responsáveis, quase que exclusivamente, pela manutenção das relações sociais (de cuidados) e pela prestação de serviços aos outros 6 .

Em contrapartida, ser homem seria associado à invulnerabilidade, força e virilidade. Características essas, incompatíveis com a demonstração de sinais de fraqueza, medo, ansiedade e insegurança, representada pela procura aos serviços de saúde, o que colocaria em risco a masculinidade e aproximaria o homem das representações de feminilidade. Percebe-se essa associação entre homem e invulnerabilidade no Grupo II, ao ser afirmado que "o que mais impede dele se cuidar é que ele acha sempre que ele é um super-herói" (Marcelo). E, "por conta dessa fortaleza parece que o homem tem uma certa invulnerabilidade" (Marcos).

O fato de apenas os entrevistados de curso superior terem falado sobre invulnerabilidade masculina não significa necessariamente que só eles utilizaram essa idéia. Mas pode significar que eles estariam mais conscientes acerca disso. Esse dado reforça conclusões de estudos sobre a invulnerabilidade como um dos eixos da construção da masculinidade 1,26,31. Associada a isso, está a dificuldade que os homens têm de verbalizar o que sentem, pois falar de seus problemas de saúde pode significar uma possível demonstração de fraqueza, de feminilização perante os outros 4 .

Outra explicação dos entrevistados, principalmente no que se refere ao Grupo I, se articula às questões relacionadas ao trabalho. A título ilustrativo destacam-se os seguintes depoimentos:

“... Pra pessoa cuidar da saúde tem que (...) fica dificil pra gente (...) que trabalha (...) não tem um tempo suficiente" (Alberto).

“... Eu acho que é mais o tempo [que falta]. Final de semana só tem médico particular. Particular já fica meio difícil para (...) pra gente (...) pagar" (Avelino).

Essas falas representam um lugar comum, revelando que o horário de funcionamento dos serviços de saúde não atende às demandas dos homens, por coincidir com a carga horária de trabalho. Como as atividades laborativas vêm em primeiro lugar na lista de preocupações masculinas, principalmente para os sujeitos do Grupo I, a busca por esses serviços fica em segundo plano. Faz-se necessário observar que esse problema pode não estar reduzido apenas aos homens. Os horários de funcionamento das instituições públicas de saúde nem sempre são conciliáveis com os horários das pessoas que se encontram inseridas no mercado de trabalho formal, independentemente de serem homens ou mulheres.

Nas falas do Grupo I, a precarização dos serviços públicos em relação ao atendimento também está presente. Os homens desse grupo, ao procurarem o serviço de saúde para uma consulta, enfrentam filas, podendo levá-los a "perder" o dia de trabalho, sem que necessariamente tenham suas demandas resolvidas em uma única consulta e, por questões econômicas, eles não podem buscar um atendimento privado:

"Você tem que marcar (...) e pago não tem condições de pagar. Aí não tem condições do homem se cuidar" (Almir).

"Tem pai de família também que ganha só um salário. (...) Vai pagar uns exames? (...) E o atendimento do (...) INSS, você sabe que é péssimo ..." (Adalberto).

No Grupo I, talvez pelo fato de haver menor poder aquisitivo em relação ao Grupo II, as preocupações foram mais direcionadas para o trabalho, para o sustento da casa e da família do que com questões relativas a cuidados de saúde, reforçando os papéis historicamente atribuídos aos homens, de que eles têm de prover o sustento da casa, garantindo a subsistência da família.

A associação entre ser provedor e ser homem ainda se encontra muito presente no imaginário social. Num estudo realizado com uma amostra de 2 mil indivíduos maiores de 18 anos, em 24 estados brasileiros, verificou-se uma forte associação da função de provedor à figura masculina. Isso é tão significativo a ponto de a co-participação da mulher na provisão das famílias, encabeçadas por homem, não ter ainda uma visibilidade social 32

Apesar de o Grupo II também ter uma preocupação com o trabalho, tal preocupação segue uma lógica distinta da do Grupo I, pois esta se caracteriza pela ascensão e sucesso de carreira que atrapalhariam ou interromperiam o cuidado com a saúde: "Eu acho que a maior dificuldade de um homem é de (...) progredir no emprego que ele tem, conseguir um cargo que ele está almejando, esse tipo de coisa, mas internamente ele (...) está se destruindo completamente ...” (Murilo).

Esse depoimento acrescenta mais uma idéia à discussão. Trata-se do fato de que, às vezes, além de o trabalho impedir a procura por serviços de 
saúde, o exercício dele também pode comprometer o ser saudável. Pelo fato de o trabalho se constituir uma função atribuída socialmente ao homem, a possibilidade de não se conseguir progresso no espaço laborativo ou a perda do emprego podem gerar tensões não somente econômicas, mas também de identidades 29.

Outra explicação para a pouca procura masculina pelos serviços de saúde, em ambos os grupos, se relaciona ao medo de descobrir que algo vai mal. O depoimento que segue é ilustrativo desse sentimento: "Eu acho que tem (...) um temor terrível (...) de encarar qualquer possibilidade de que algo vai mal" (Murilo).

Esse sentimento costuma ser comum nas pessoas, independente do gênero. Assim, como no ditado popular de "quem procura acha", os sujeitos temem que, ao buscar um serviço de saúde para saber se a sua saúde vai bem, possa se deparar com diagnósticos de uma doença e ter de se tratar. No caso específico da prevenção de câncer, há estudos que apontam que o medo é uma das explicações para o fato de as pessoas não procurarem os serviços de saúde para se prevenirem 33,34 .

A vergonha de ficar exposto a um outro homem ou a uma mulher também é uma explicação para a não busca de cuidados médicos por parte dos homens. Nesse caso, o acervo utilizado que se refere à temática de câncer de próstata, os depoimentos dos homens indicam as resistências em ter de mostrar partes de seu corpo tão íntimas, o que seria demandado numa situação de exame de próstata. Essa resistência foi citada como um dos fatores que dificultam o acesso masculino aos serviços de saúde:

“Acho que (...) tudo que diga respeito às partes genitais (...) o pênis (...) o testículo, examinar o ânus, eu acho que é tudo que fique nessa região das genitais, fica um pouco mais difícil ..." (Marcos).

“Tem (...) muito homem que está doente, está morrendo. Mas tem vergonha de falar com o médico que está com (...) aquele problema ali" (Alex).

Possivelmente essa vergonha se associa à falta de hábito de se expor ao médico. Ao contrário, a mulher em sua socialização foi mais acostumada a ter o seu corpo exposto para a medicina. Com a preocupação da sífilis e outras doenças venéreas, no final do século XIX e nas primeiras décadas do século XX, o corpo masculino passou a ser mais devassável. Entretanto, a lógica do olhar médico sobre esse corpo se relacionou mais à doença que vem de fora que pode comprometer a sua descendência. Já em relação às mulheres, principalmente com a criação da ginecologia, desenvolveu-se um olhar mais abrangente, passando a existir uma maior medicalização de seu corpo, ao longo dos seus diferentes ciclos de vida ${ }^{35}$. Essa assimetria entre os gêneros, no que se refere ao olhar da medicina, pode ter contribuído para que a exposição da mulher seja vista como mais natural do que a do homem.

A falta de unidades de saúde específicas para o cuidado com o homem também foi apontada, principalmente no Grupo I, como barreira para o acesso dos homens aos serviços de saúde:

“... Deveria ter um (...) tipo um hospital para fazer (...) atendimentos só para homens” (Adalberto).

Isso não ocorreu no Grupo II; talvez pelo fato de haver neste grupo um maior poder aquisitivo por parte de seus membros, possibilitando-os a ter planos de saúde ou acessarem serviços privados de saúde.

Em geral, pesquisas confirmam as dificuldades do acesso masculino aos serviços de saúde. Uma investigação realizada em São Paulo, Brasil 36, com homens de baixa renda, sobre saúde sexual, concluiu que havia escassez e inadequação tanto para os homens que dependiam dos serviços públicos de saúde quanto para aqueles que possuíam planos de saúde oferecidos pelo sindicato. Os estudos apontam também para o fato de homens não se reconhecerem como alvo do atendimento de programas de saúde, devido às ações preventivas se dirigir quase que exclusivamente para mulheres 36,37 .

Assim, os serviços públicos costumam ser percebidos como um espaço feminilizado, freqüentado principalmente por mulheres e composto por uma equipe de profissionais formada, em sua maioria, também por mulheres. Essa situação provocaria nos homens a sensação de não pertencimento àquele espaço.

\section{A procura por ajuda}

Segundo alguns entrevistados do Grupo II, também há momentos em que se busca ajuda para a cura de um mal que aflige. Isso, em geral, ocorre por dois motivos: quando a dor se torna insuportável e quando há uma impossibilidade de trabalhar:

"Eu só vou ao médico quando eu sinto alguma coisa" (Marcelo).

"Geralmente, falando dos homens, só consertam a fechadura depois que a porta foi arrombada, não é? Ou seja, só vai ao médico na hora que sente dor" (Mateus).

No Grupo I, alguns entrevistados trouxeram a idéia de que, quando os homens sentem alguma coisa, eles procuram medidas de tratamento alternativas, como tomar alguma medicação por 
conta própria, tomar algum chá ou se medicar utilizando-se da orientação de algum farmacêutico. Essas saídas encontradas por eles para melhorar sua saúde são mais pontuais, não o fazendo perder tempo com filas, com a espera pelo atendimento médico:

"O homem não liga para nada. Estou com doença nada. Toma um remédio, toma um chá" (Adalberto).

“... Hoje está bom, faz e acontece. Amanhã, está com problema de (...) ah [vai à] farmácia ..." (Alex).

"Muito difícil o homem (...) lembrar de médico. Só quando (...) ele está sempre nas últimas (...) ele vai procurar (...) pronto socorro" (Adalberto).

Há estudos, a exemplo de Pinheiro et al. 5 , que apontam a prevalência masculina na procura de serviços emergenciais, tais como farmácia e pronto-socorro. Talvez os homens preferiram utilizar as farmácias ou prontos-socorros porque esses responderiam mais objetivamente às suas demandas. Nesses espaços, os homens seriam atendidos mais rapidamente e conseguiriam expor seus problemas com mais facilidade 4 . A farmácia, em específico, tem um papel importante na relação que o homem estabelece com sua saúde, pois esta é vista como uma instância "semiprofissional" onde se pode pedir um conselho em serviço médico, sem precisar enfrentar filas ou marcar consultas. Como a primeira urgência em geral é aliviar a dor, muitas vezes a visita à farmácia satisfaz esta necessidade mais rapidamente $?$.

Ainda em relação à ida de homens a serviços de saúde, observamos que o espaço do trabalho, além de dificultar, também pode facilitar:

"Ninguém procura [médico ou serviços de saúde]. Só quando a firma mesmo exige" (Adalberto).

"Só mesmo assim, porque para a gente fichar [fazer o cadastro de trabalho] (...) a firma manda [fazer exames rotineiros]" (Avelino).

Essas falas revelam que, ainda que pontualmente ou para cumprir exigências burocráticas, as demandas das empresas empregadoras podem suscitar momentos de prevenção ou de cuidados em saúde. Nesse sentido, tais demandas poderão ser compreendidas como um espaço a ser investido para ações preventivas, desde que promovam um maior envolvimento dos sujeitos nessas ações e que não incorram numa simples medicalização.

\section{Considerações finais}

Como foram vistos, os dados da pesquisa reforçaram, de certa forma, a idéia de outros estudos que associam a pouca procura por serviços de saúde por parte de homens a um modelo hegemônico de masculinidade. No entanto, como também foi verificado, nem sempre os entrevistados reproduziam tal modelo. Em geral, revelaram certa ambigüidade: ora utilizavam idéias predominantes no senso comum para construírem os seus discursos sobre a masculinidade, ora criticavam tais idéias, assumindo uma opinião pessoal, flexibilizando o que hegemonicamente é colocado neste mesmo senso comum.

As inferências deste estudo apontaram que o imaginário de ser homem pode aprisionar o masculino em amarras culturais, dificultando a adoção de práticas de autocuidado, pois à medida que o homem é visto como viril, invulnerável e forte, procurar o serviço de saúde, numa perspectiva preventiva, poderia associá-lo à fraqueza, medo e insegurança; portanto, poderia aproximá-lo das representações do universo feminino, o que implicaria possivelmente desconfianças acerca dessa masculinidade socialmente instituída.

Uma outra questão que reforça a ausência dos homens ao serviço de saúde seria o medo da descoberta de uma doença grave, assim, não saber pode ser considerado um fator de "proteção" para os homens estudados. Outra dificuldade para o acesso dos homens a esses serviços é a vergonha da exposição do seu corpo perante o profissional de saúde, particularmente a região anal, no caso da prevenção ao câncer de próstata. Também é apontado como um fator que dificulta esse acesso a falta de unidades específicas para o tratamento da saúde do homem.

Os serviços de saúde também são considerados pouco aptos em absorver a demanda apresentada pelos homens, pois sua organização não estimula o acesso e as próprias campanhas de saúde pública não se voltam para este segmento. Além disso, o mercado de trabalho geralmente não garante formalmente a adoção de tal prática, portanto, o homem em dado momento pode ser prejudicado e sentir seu papel de provedor ameaçado.

O fato dos homens do Grupo II terem curso superior fez a diferença na adoção de um posicionamento crítico. Esses entrevistados foram capazes de problematizar com uma maior propriedade intelectual sobre o tema, além de apresentarem idéias consideradas "politicamente corretas”. Entretanto, alguns deles observaram que, mesmo considerando que os homens deveriam cuidar de sua saúde, nem sempre conseguiam agir de acordo com essa idéia. Esse dado reforça o que na literatura vem sendo apontado sobre a diferença entre o que deveria ser e o que é a saúde para os homens. Discursivamente, ho- 
mens costumam mencionar a saúde como uma situação ideal, mas este discurso não se traduz nas suas vivências $?$.

Por último, os resultados do estudo podem ajudar na discussão da possível contradição entre os dados epidemiológicos (que vêem o homem como mais vulnerável do que as mulheres) e o senso comum (que vê o homem como mais invulnerável). Podem subsidiar o debate no sentido de revelar que essas idéias, aparentemente contraditórias, se complementam. Ou seja, os homens por se sentirem invulneráveis se expõem mais e acabam ficando vulneráveis. São duas faces da mesma moeda.

\section{Resumo}

O estudo tem como objetivo analisar as explicações presentes em discursos masculinos para a pouca procura dos homens por serviços de saúde. O método do estudo baseia-se numa abordagem de pesquisa qualitativa. A representação do cuidar como tarefa feminina, as questões relacionadas ao trabalho, a dificuldade de acesso aos serviços e a falta de unidades especificamente voltadas para a saúde do homem são os principais motivos expressos pelos sujeitos para a pouca procura pelos serviços de saúde. Conclui-se, dentre outros aspectos, que o imaginário social que vê o homem como ser invulnerável acaba contribuindo para que ele menos se cuide e mais se exponha a situações de risco.

Saúde do Homem; Serviços de Saúde; Identidade de Gênero

\section{Colaboradores}

R. Gomes coordenou a pesquisa original e participou da coleta e análise dos dados, bem como da redação final do trabalho. E. F. Nascimento e F. C. Araújo participaram da análise dos dados e da redação final do trabalho.

\section{Agradecimentos}

Ao Conselho Nacional de Desenvolvimento Científico e Tecnológico que proporcionou o desenvolvimento da pesquisa intitulada A Construção da Masculinidade como um Fator Impeditivo do Cuidar de Si, que gerou este artigo. 


\section{Referências}

1. Courtenay WH. Constructions of masculinity and their influence on men's well-being: a theory of gender and health. Soc Sci Med 2000; 50:1385-401.

2. Laurenti R, Mello-Jorge MHP, Gotlieb SLD. Perfil epidemiológico da morbi-mortalidade masculina. Ciênc Saúde Coletiva 2005; 10:35-46.

3. Luck M, Bamford M, Williamson P. Men's health: perspectives, diversity and paradox. London: Blackwell Sciences; 2000.

4. Figueiredo W. Assistência à saúde dos homens: um desafio para os serviços de atenção primária. Ciênc Saúde Coletiva 2005; 10:105-9.

5. Pinheiro RS, Viacava F, Travassos C, Brito AS Gênero, morbidade, acesso e utilização de serviços de saúde no Brasil. Ciênc Saúde Coletiva 2002; 7:687-707.

6. Lyra-da-Fonseca JLC, Leão LS, Lima DC, Targino P, Crisóstomo A, Santos B. Homens e cuidado: uma outra família? In: Acosta AR, Vitale MA, organizadores. Família: redes, laços e políticas públicas. São Paulo: Instituto de Estudos Especiais, Pontifícia Universidade Católica de São Paulo; 2003. p. 79-91.

7. Tellería JM. Reflexiones autocríticas acerca de una investigación sobre la búsqueda de atención y demandas en salud de hombres en Santa Cruz de La Sierra - Bolivia. In: Cáceres CF, Cueto M, Ramos M, Vallas S, editors. La salud como derecho ciudadano: perspectivas y propuestas desde América Latina. Lima: Universidad Peruana Cayetano Heredia; 2003. p. 165-72.

8. Gomes R. Sexualidade masculina e saúde do homem: proposta para uma discussão. Ciênc Saúde Coletiva 2003; 8:825-9.

9. Keijzer B. Hasta donde el cuerpo aguante: género, cuerpo y salud masculina. In: Cáceres CF, Cueto M, Ramos M, Vallas S, editors. La salud como derecho ciudadano: perspectivas y propuestas desde América Latina. Lima: Universidad Peruana Cayetano Heredia; 2003. p. 137-52.

10. Schraiber LB, Gomes R, Couto MT. Homens na pauta da saúde coletiva. Ciênc Saúde Coletiva 2005; 10:7-17.

11. World Health Organization. Boys in the picture. Geneva: World Health Organization; 2000.

12. Oliveira PP. A Construção social da masculinidade. Belo Horizonte: Editora UFMG; 2004.

13. Petersen A. Unmasking the masculine: "men" and "identity" in a sceptical age. London: Sage Publications; 1998.

14. Welzer-Lang D. A construção do masculino: dominação das mulheres e homofobia. Revista Estudos Feministas 2001; 2:460-82.

15. Bourdieu P. A dominação masculina. Rio de Janeiro: Bertrand Brasil; 1999.

16. Welzer-Lang D. Os homens e o masculino numa perspectiva de relações sociais de sexo. In: Schpun MR, organizador. Masculinidades. Santa Cruz do Sul: EDUNISC; 2004. p. 107-28.

17. Foucault M. História da sexualidade - 3: o cuidado de si. Rio de Janeiro: Edições Graal; 1985.
18. Denzin NK, Lincoln YS. Introduction: the discipline and practice of qualitative research. In: Denzin NK, Lincoln YS, editores. Handbook of qualitative research. London: Sage Publications; 2000. p. 1-29.

19. Deslandes SF, Gomes R. A pesquisa qualitativa em serviços de saúde: notas teóricas. In: Bosi MLM, Mercado FJ, organizadores. Pesquisa qualitativa de serviços de saúde. Petrópolis: Editora Vozes; 2004. p. 99-120.

20. Minayo MCS, Souza ER, Constantino P, Santos NC. Métodos, técnicas e relações em triangulação. In: Minayo MCS, Assis SG, Souza ER, organizadores. Avaliação por triangulação de métodos: abordagem de programas sociais. Rio de Janeiro: Editora Fiocruz; 2005. p. 71-103.

21. Vaitsman J. Flexíveis e plurais: identidade, casamento e família em circunstâncias pós-modernas. Rio de Janeiro: Editora Rocco; 1994.

22. Velho G. Individualismo e cultura. Rio de Janeiro: Jorge Zahar Editor; 1981.

23. Minayo MCS. O desafio do conhecimento: pesquisa qualitativa em saúde. São Paulo: Editora Hucitec; 2002.

24. Gomes R, Souza ER, Minayo MCS, Silva CFR. Organização, processamento, análise e interpretação de dados: o desafio da triangulação. In: Minayo MCS, Assis SG, Souza ER, organizadores. Avaliação por triangulação de métodos: abordagem de programas sociais. Rio de Janeiro: Editora Fiocruz; 2005. p. 185-221.

25. Bozon M. Sociologia da sexualidade. Rio de Janeiro: Editora FGV; 2004.

26. Sabo D. O estudo crítico das masculinidades. In. Adelman M, Silvestrin CB, organizadores. Coletânea gênero plural. Curitiba: Editora UFPR; 2002. p. 33-46.

27. Almeida A. Marido: quando você vai fazer sexo anal comigo? Mulher: vou pensar no assunto. Inteligência 2005; 29:67-78.

28. Ceccheto FR. Violência e estilos de masculinidades. Rio de Janeiro: Editora FGV; 2004

29. Hardy E, Jiménez AL. Masculinidad y género. In: Briceño-León R, Minayo MCS, Coimbra Jr. CEA, editors. Salud y equidad: una mirada desde las ciencias sociales. Rio de Janeiro: Editora Fiocruz; 2000. p. 349-59.

30. Medrado B, Lyra-da-Fonseca JLC, Leão LS, Lima DC, Santos B. Homens jovens no contexto do cuidado: leituras a partir da paternidade na adolescência. In: Adorno R, Alvarenga A, Vasconcelos MP, organizadores. Jovens, trajetória, masculinidades e direitos. São Paulo: Edusp; 2005. p. 241-64.

31. Korin D. Novas perspectivas de gênero em saúde. Adolescência Latino-Americana 2001; 2:1-16.

32. Oliveira ZLC. A provisão da família: redefinição ou manutenção dos papéis? In: Araújo C, Scalon C, organizadores. Gênero, família e trabalho no Brasil. Rio de Janeiro: Editora FGV; 2005. p. 123-47.

33. Zerbib M, Perez M. Próstata: 100 perguntas e respostas. São Paulo. Editora Larousse do Brasil; 2003. 
34. Sociedade Brasileira de Urologia. Sua saúde urológica. http://www.sbu.org.br/site/1/saudeUrologica. php (acessado em 09/Ago/2005).

35. Rohden F. Uma ciência da diferença: sexo e gênero na medicina da mulher. Rio de Janeiro: Editora Fiocruz; 2001. (Coleção Antropologia \& Saúde).

36. Kalckmann S, Batista LE, Souza LCF. Homens de baixa renda falam sobre saúde reprodutiva e sexual. In: Adorno R, Alvarenga A, Vasconcelos MP, organizadores. Jovens, trajetória, masculinidades e direitos. São Paulo: Edusp; 2005. p. 199-217.
37. Schraiber LB. Eqüidade de gênero e saúde: o cotidiano das práticas no Programa Saúde da Família do Recife. In: Villela W, Monteiro S, organizadores. Gênero e saúde: Programa Saúde da Família em questão. Rio de Janeiro: ABRASCO/Brasília: Fundo de População das Nações Unidas; 2005. p. 39-61.

Recebido em 26/Jan/2006

Versão final reapresentada em 19/Jun/2006 Aprovado em 04/Set/2006 